\title{
Pecs block for anesthesia in breast surgery of the elderly
}

\author{
Hiroaki Murata $\cdot$ Taiga Ichinomiya $\cdot$ Tetsuya Hara
}

Received: 28 November 2014 / Accepted: 16 February 2015 / Published online: 4 March 2015

(C) Japanese Society of Anesthesiologists 2015

Keywords Pecs block · Breast surgery $\cdot$ Anesthesia

\section{To the Editor:}

Pecs block is usually used as perioperative analgesia for breast surgery $[1,2]$. Local anesthetic is injected between the pectoralis major (PMm) and minor (Pmm) muscles for a Pecs I block, and between the serratus anterior muscle and Pmm for a Pecs II block. We have used the Pecs block as an anesthesia technique in breast surgery of the elderly.

Case 1 was a 91-year-old female $(140 \mathrm{~cm}, 32 \mathrm{~kg})$ who presented for simple mastectomy for a large breast tumor. The Pecs II block was achieved by use of $35 \mathrm{~mL} 0.2 \%$ ropivacaine. Surgery was completed uneventfully with additional local anesthetic infiltration. Case 2 was a 94-year-old female $(138 \mathrm{~cm}, 34 \mathrm{~kg})$ who presented for lumpectomy of a breast tumor located close to the PMm. The Pecs I and II blocks were achieved with a total of $45 \mathrm{~mL} 0.2 \%$ ropivacaine. Surgery was completed uneventfully.
H. Murata $(\bowtie) \cdot$ T. Ichinomiya $\cdot$ T. Hara

Department of Anesthesiology, Nagasaki University School of Medicine, 1-7-1 Sakamoto, Nagasaki 852-8501, Japan

e-mail: h-murata@nagasaki-u.ac.jp
For the Pecs block, to achieve wider coverage of the skin dermatome while avoiding the risk of local anesthetic toxicity, we used ropivacaine in a greater volume and at a lower concentration than the original regimen [2]. A Pecs block, with a sufficient volume of local anesthetic, may be a good option as anesthesia for breast surgery of the elderly.

Conflict of interest None.

\section{References}

1. Bashandy GM, Abbas DN. Pectoral nerves I and II blocks in multimodal analgesia for breast cancer surgery: a randomized clinical trial. Reg Anesth Pain Med. 2015;40:68-74.

2. Blanco R, Fajardo M, Parras Maldonado T. Ultrasound description of Pecs II (modified Pecs I): a novel approach to breast surgery. Rev Esp Anestesiol Reanim. 2012;59:470-5. 